\title{
Fused thiophenes: an overview of the computational investigations
}

\author{
Fatma Dikcal, Turan Ozturk* and M. Emin Cinar* \\ Department of Chemistry, Istanbul Technical University, Maslak, \\ Istanbul 34469, Türkiye
}

\section{(Received April 4, 2017; Revised April 11, 2017; Accepted April 24, 2017)}

\begin{abstract}
Computational investigations of fused thiophenes including not only thienothiophene, ditihienothiophene and thienoacene but also other thiophene-fused (hetero)-aromatic rings have been surveyed. The effect of the methods and basis sets applied on promising optoelectronic materials were elaborated. This brief review suggests the best method for the fused thiophenes to be B3LYP functional. C2016 ACG Publications. All rights reserved.
\end{abstract}

Keywords: Computation; DFT; fused thiophenes; optoelectronic. (C) 2017 ACG Publications. All rights reserved.

\section{Introduction}

Conjugated organic compounds have been the focus of scientists due to their promising use in organic thin film transistors (TFT) ${ }^{1-5}$ and solar cells. ${ }^{6,7}$ They have less processing time and cost through their deposition from solution providing a fast and large-area fabrication. ${ }^{8}$ Fused thiophenes provide a better conjugation in the ground state and are utilized for tuning the band gap of organic materials owing to their rigid structures with an extended $\pi$-conjugation. Moreover, they enhance the intermolecular interactions in thin films which influence the molecular arrangement predominantly.,10

Fused thiophenes comprise thienothiophenes (TTs), possessing two annulated thiophene rings, dithienothiophenes (DTTs), formed by fusing another thiophene ring to TTs, and thienoacenes having more than three thiophene units. $9^{10}$ Thiophenes were also annulated to other aromatic units, such as pyrrole, furan, benzene, pyridine, etc.

To shed light on the optoelectronic properties of organic materials, which were aimed to be used in TFT, organic light emitting diodes (OLEDs) and solar cells, their computational investigations using density functional theory (DFT) and time dependent-DFT (TD-DFT) were conducted. Estimated electronic and structure characteristics of the most appropriate candidates were compared with those collected from experimental studies to open a new avenue for the construction of highly efficient optoelectronic materials.

In this brief review, computational investigations performed to unveil the optoelectronic properties of oligomers and polymers possessing fused thiophenes will be addressed.

\footnotetext{
* Corresponding authors: E-Mail: ozturktur@itu.edu.tr , Tel: +90 212 2856994; Fax: +90 2122856386

E-Mail: emin.cinar@ uni-siegen.de, Tel: +90 5342013823 ; Fax: +90 2122856386.
} 


\section{Thiophene-Based Fused Systems}

Recently, annulated thiophene systems have attracted remarkable interest, and they have been investigated theoretically and experimentally, owing to their various practical applications. Numerous publications reporting diverse aspects of the chemistry of fused thiophenes unequivocally confirm the growing interest in their material chemistry. ${ }^{11}$

Fused thiophenes, such as thienothiophenes (TTs), possess more rigid structures than $\alpha$ oligothiophenes, containing two or more thiophene rings linked through a single bond. They have attracted considerable attention as they have excellent electrochemical and optical properties. ${ }^{12}$ Oligothiophene and fused thiophene based conjugated materials could have highly $\pi$-conjugated electrical conductance with promising potential applications in organic light-emitting diodes (OLEDs) ${ }^{13-17}$ organic photovoltaic cells $(\mathrm{OPVs})^{18-23}$ organic field-effect transistors $(\mathrm{OFETs})^{24-27}$ and dye-sensitized solar cells (DSSCs). ${ }^{28}$

Fused thiophene-based materials have emerged as one of the most promising alternatives, and led to high charge carrier mobilities exceeding $1 \mathrm{~cm}^{2} \mathrm{~V}^{-1} \mathrm{~s}^{-1}$ together with excellent stability and processability. ${ }^{29,30}$

\subsection{Structural and Electronic Properties of Fused Thiophene Based Systems and Their Application Areas}

Annulation of thiophenes limits the rotational disorders between thiophene rings in favor of creating better conjugation, ${ }^{31}$ which, as a result, provides conjugated systems with low band gaps. Their stable and electron rich structures make them important building blocks for the construction of OPVs and OTFTs. ${ }^{32,33}$ DTT and its isomers demonstrated various intermolecular interactions including weak hydrogen bonding, $\pi-\pi$ stacking, $\mathrm{C}-\mathrm{H}$ interactions, and $\mathrm{S}-\mathrm{S}$ interactions. $^{34}$ In case of the dimer of the fused thiophene, $\alpha, \alpha^{\prime}$-bis(dithieno[3,2-b:2', 3'$d$ ] thiophene) (BDT) was found to have an unusual $\pi$-stacking rendering a high mobility up to 0.05 $\mathrm{cm}^{2} \mathrm{~V}^{-1} \mathrm{~s}^{-1} .{ }^{35}$ These endowed features allow it to be utilized in organic electronic devices. ${ }^{36}$ Organic acceptor and donor molecules based on DTT were used for the preparation of different cation radical salts and charge-transfer complexes. ${ }^{37,38}$

Acenes are polycyclic aromatic hydrocarbons consisting of linearly fused benzene rings. Although acenes containing five or more fused aromatic rings have been long known as promising materials for organic electronic devices, ${ }^{39}$ their instabilities against light and air hamper their use in material chemistry. ${ }^{40,41}$ Unlike acenes, thienoacenes containing annulated thiophene rings possess higher charge mobilities and stabilities under ambient conditions, owing to their favorable electronic properties. For example, dithieno[2,3-d:2',3'-d']thieno[3,2-b:4,5$b^{\prime}$ ']dithiophene (pentathienoacene, PTA) has a molecular shape and crystal packing geometry similar to those of pentacene, whereas the larger band gap (up to $3.29 \mathrm{eV}$ ) of PTA compared to that of pentacene $(1.85 \mathrm{eV})$ indicates the stability of PTA toward visible light. ${ }^{42}$

\subsection{Computational Studies on Thiophene Based Fused Systems}

Although various synthetic methods are available in the literature, theoretical studies for the formation mechanism of oligo- and fused-thiophenes are rather rare. In addition, experimental and computational investigations on their electronic transport properties still need extensive effort. $^{43,44}$

Based on thorough theoretical works, the donor-acceptor (D-A) strategy among all approaches has been the most useful one applied in material chemistry such as in search of green electrochromic polymers and chromophores containing DTTs. ${ }^{32,45,46}$ Electrochemical and spectroscopic properties of the neutral and doped forms of $\mathrm{D}-\pi-\mathrm{A}$ chromophores possessing DTTs were investigated by means of FT-Raman and Vis-NIR spectroscopies combined with DFT methods. These chromophores are used as electron relay $\pi$-centers to improve the electronic properties of $\pi$-conjugated molecules. ${ }^{45,46}$ 
Dithieno[3,2-b:2', $\left.3^{\prime}-d\right]$ thiophene (1) and dithieno[2,3-b:3', $\left.2^{\prime}-d\right]$ thiophene (2), obtained through the annulation of bithiophenes by bridging the $\alpha, \alpha^{\prime}$ and $\beta, \beta^{\prime}$ positions with a sulfur atom had quite different LUMO characters and, therefore, significant difference between their HOMO-LUMO gaps was observed. ${ }^{47}$ While the former with a good conjugation had a gap of 4.51 $\mathrm{eV}$, the latter one possessing a cross-conjugated system was calculated to have $5.27 \mathrm{eV}$ of HOMO-LUMO gap (Figure 1, left). Moreover, HOMO-LUMO gaps and spin densities were also computed for diaryl-substituted dithieno[2,3-b:3',2'-d]-thiophenes (3a-3d) to shed light on the electropolymerization of cross-conjugated DTTs. Taskiran Cankaya et $\mathrm{al}^{48}$ performed the DFT calculations on 3a-3d bearing $p$-substituted phenyl units at 3- and 4-positions at UB3LYP/6$31+\mathrm{G}(\mathrm{d})$ level (Figure 1, middle). Although the cross-conjugated DTTs had enough spin densities on $\alpha$-carbons, which are best places for an electro-polymerization based on computations, all attempts for their electrochemical polymerizations ended up with failure. This result was explained by almost zero spin densities on related $\alpha$-carbon atoms in dimer, which prevented the polymerization. (Figure 1, right).
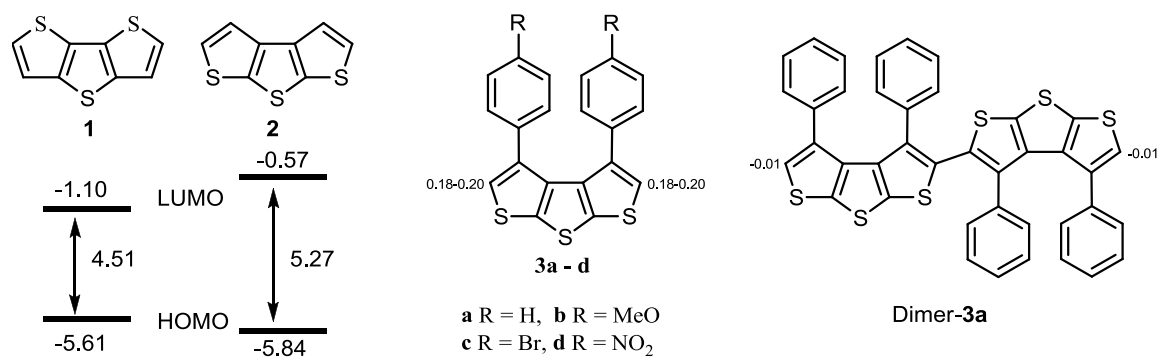

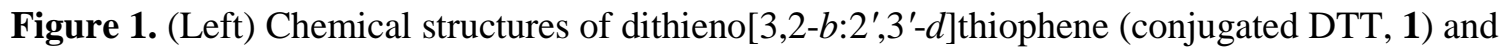
dithieno[2,3-b:3', $\left.2^{\prime}-d\right]$-thiophene (cross-conjugated DTT, 2), and their HOMO and LUMO energy levels in eV. ${ }^{47}$ (Middle) Diaryl-substituted cross-conjugated DTTs 3a-3d and the range of spin densities on $\alpha$-carbons. (Right) Dimer of $\mathbf{3 a}$ and the spin densities on $\alpha$-carbons required for electropolymerization. ${ }^{48}$

Comprehensive computations on dimers were performed by $\mathrm{Li}$ et $\mathrm{al}^{47}$ at B3LYP/6$31 \mathrm{G}(\mathrm{d}, \mathrm{p})$ level to unveil the effects of structural symmetry and linking mode on the electronic structures of the dimers, which made of accurate description of the ground-state electronic properties and electronic couplings between adjacent molecules ( displayed in

Figure 2, above). The predicted FMO plots and orbital energy levels of the dimers are

Figure 2 (below). Dimerization of $\alpha$ - and $\beta$-DTTs resulted in higher HOMOs and lower LUMOs, and consequently smaller HOMO-LUMO gaps for molecules $\mathbf{4}$ and $\mathbf{5}$, compared to their monomers. Further decrease in HOMO-LUMO gaps was achieved through incorporation of a vinylene bridge (4-6), possessing relatively smaller HOMO-LUMO gaps with respect to 4-6. The effect of substituents on dimers was probed by attachment of phenyl (8b) and 2-thienyl (8c) to $\alpha$-positions of dimer 8a. The total density of states (DOS) and projected density of states (PDOS) of three dimers 8a-8c indicated that the sulfur atoms partially take part in the formation of both HOMOs and LUMOs, while the phenyl and 2-thienyl groups are not involved at all. Owing to the dihedral angles between phenyl or thienyl groups and the central $\pi$ systems about $29.2^{\circ}$ and $25.2^{\circ}$, respectively, the substituted phenyl or thienyl groups $(\mathbf{8 b}$ and $\mathbf{8 c}$ ) cannot extend the conjugation of $\pi$-system efficiently and only partly take place in the charge transport, whereas the sulfur atoms directly involved in the charge carrier transport (8a). The molecular geometries, the frontier molecular orbitals, molecular ionization potentials (IPs), electron affinities (EAs) and reorganization energies were proved to be influenced by the structural symmetry and linking mode in dimerization. 

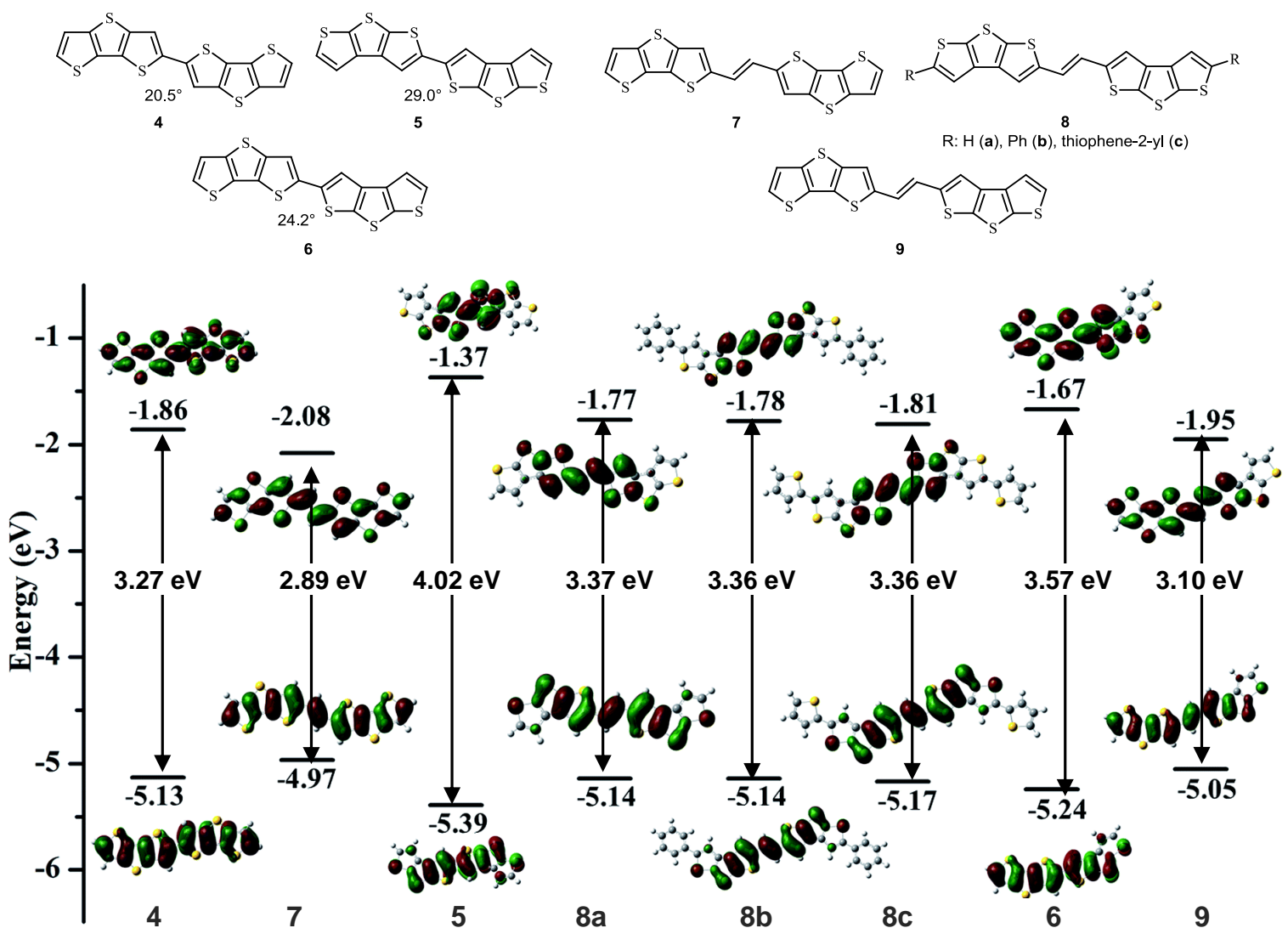

Figure 2. (Above) Dimers of DTTs 4-9 and dihedral angles for 4-6. (Below) Their HOMO and LUMO energy levels and surfaces estimated at B3LYP/6-31G(d,p) level. "Reprinted (adapted) with permission from Li, P.; Cui, Y.; Song, C.; Zhang, H. RSC Adv., 2015, 5, 50212-50222. Copyright 2015 The Royal Society of Chemistry (RSC)."

The relationship between geometric structures and electronic properties of fused thiophenes was investigated in depth by Park et $\mathrm{al}^{49}$ (Figure 3, left). Molecular structures of all $\alpha$ ([n]TA (thienoacenes)) and $\beta$-annulated ([n]TH (thienohelicenes)) thiophenes were optimized using B3LYP/6-31G(d) method, which indicated that there is a close linear relationship between HOMO-LUMO gaps $\left(E_{\mathrm{g}}\right)$ and 1/Nc (Nc: number of $\mathrm{C}$ atoms) (Figure 3, right). The intercepts of the graphs provided the band gaps of 2.235 and $4.152 \mathrm{eV}$ for TAs and THs, respectively. The slopes showed that the conjugation length affecting the HOMO-LUMO gaps $(E g)$ is smaller in the TH system compared to that of TA (8.87 vs. 17.12). Based on the combined computational and experimental studies on oligothienoacenes with five and seven rings, Osuna et al ${ }^{50}$ reported that these fused oligothiophenes have a larger band gap than most semiconductors currently used in the fabrication of organic field-effect transistors (OFETs). Conjugational and optical properties of pentathienoacene (5TA) and heptathienoacene (7TA) (Figure 3), analyzed by using Raman and UV-vis-NIR absorption spectroscopies, were interpreted by DFT and TD-DFT quantum chemical calculations at the B3LYP/6-31G(d,p) level, owing to the fact that DFT is well suited to model extended $\pi$-conjugated systems. ${ }^{51}$ It was reported that singlet excited states of 5TA and 7TA, experimentally measured at $355 \mathrm{~nm}$ (5TA) and $396 \mathrm{~nm}$ (7TA), are closely related to the calculated electronic transitions of 5TA at $349(f=0.754)$ and 7TA at $397 \mathrm{~nm}(f=1.202)$. These results pointed out the high accuracy of TD-DFT approach for predicting the experimental wavelengths. On the other hand, DFT calculations allowed identification of the vibrational modes, associated with each of the strongest Raman features, selectively enhanced by the 
presence of effective $\pi$-conjugation. DFT calculations indicated totally symmetric collective vibrations mostly located on the sulfur linkages, responsible for these Raman features.
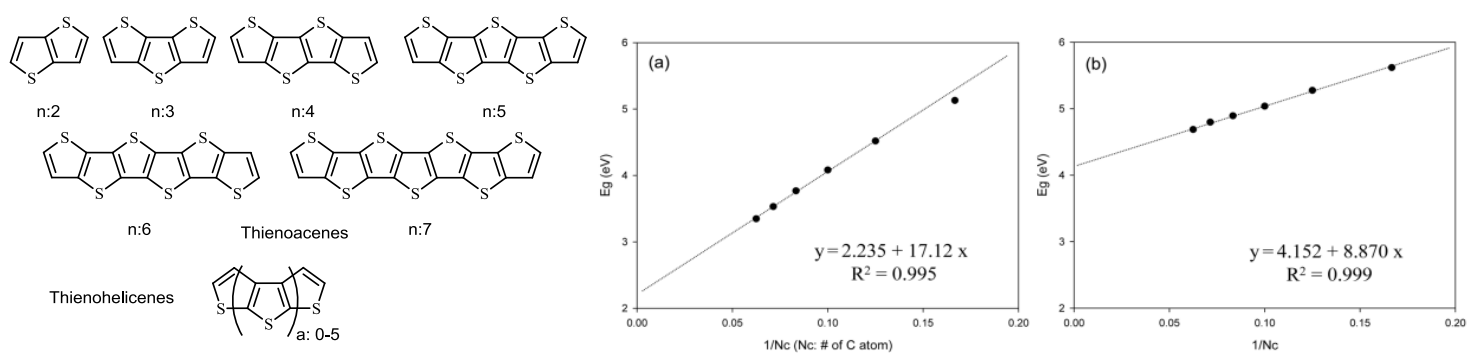

Figure 3. (Left) Chemical structures of [n]thienoacenes (TA) and [n]thienohelicenes (TH). (Right) HOMO-LUMO gaps $\left(E_{\mathrm{g}}\right)$ of [n]TA (a) and [n]TH (b) oligomers as a function of $1 / \mathrm{Nc}$, where $\mathrm{Nc}$ is the number of carbon atoms along the chain. "Reprinted (adapted) with permission from Ra, C. S.; Yim, S.; Park, G. Bull. Korean Chem. Soc. 2008, 29, 891-893. Copyright 2008 Publications of the Korean Chemical Society (KCS)." ${ }^{49}$

The influence of the length of fused thiophenes on the capabilities of the charge transfer properties of a series of multifunctional molecular devices was elaborated by Fan et al. ${ }^{52}$ Based on computations involving the combination of non-equilibrium Green's functions(NEGF) ${ }^{53}$ and firstprinciple DFT, it was reported that multifunctional molecular devices can be produced when suitable substituents are attached to the fused thiophenes, and the peak position of negative differential resistance (NDR) and rectification ratio can be controlled by changing the molecular length. The molecules having thiol end groups depicted in Figure 4 (left) were fully optimized at the B3LYP/6-31G(d,p) level. These thiol subunits were used in molecular devices to place the molecules between two gold electrodes (Figure 4, right). Geometry optimizations and transport calculations for two-probe systems were done conducting DFT computations combined with Non-Equilibrium Green's Functions (NEGF/DFT) approach. The exchange-correlation potential was described by Perdew-Burke-Ernzerh (PBE) of parametrization of the generalized gradient approximation (GGA). LDOSs (Local Density of States), MPSH (Molecular Projected SelfConsistent Hamiltonian), transmission spectra, and fermi level calculations of all two-probe systems led to the following results; a) the increase in molecular conjugation length shifts the NDR peak from the higher bias to the lower bias, b) Rectifying performance can be realized by introduction of push-pull substituent groups breaking the symmetry of molecules, c) 13c can be regard as a good candidate for multifunctional molecular device owing to its excellent rectifying performance.

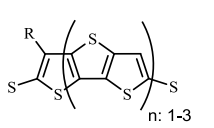

10a-c: $\mathrm{R}=\mathrm{H}$
11a-c: $\mathrm{R}=\mathrm{NO}_{2}$
12a-c: $\mathrm{R}=\mathrm{NH}_{2}$

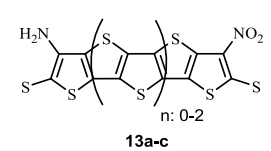

$13 a-c$

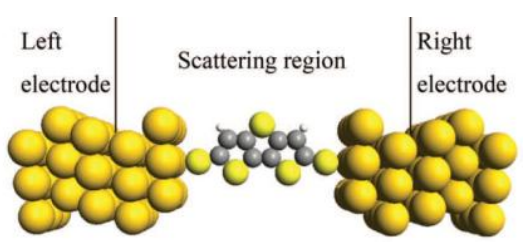

Figure 4. (Left) Chemical structures of the investigated molecules, (right) a representative model of the molecular junction; large yellow, medium yellow, medium gray and small white balls represent $\mathrm{Au}, \mathrm{S}, \mathrm{C}$ and $\mathrm{H}$ atoms, respectively. "Reprinted (adapted) with permission from Fan, J.; Gathitu, N. N.; Chang, Y.; Zhang, J. J. Chem. Phys, 2013, 138, 074307. Copyright 2013 AIP Publishing LLC. ${ }^{52}$

Although electropolymerization of cross-conjugated DTTs failed, ${ }^{48}$ conjugated TT and DTT possessing co-monomers linked through 4,4'-dinonyl-2,2'-bithiazole were polymerized successfully electrochemically by Sezer and Ustamehmetoğlu. ${ }^{54,55}$ They investigated the electrochemical and optical properties of these co-monomers PhTT-NBT-PhTT (14), containing 4,4'-dinonyl-2,2'-bithiazole and 3-phenylthieno[3,2-b]thiophene units, and T-NBT- $\mathrm{Ph}_{2} \mathrm{DTT}-\mathrm{NBT}$ - 
T (15), possessing 4,4'-dinonyl-2,2'-bithiazole and 3,5-diphenyldithieno[3,2-b;2',3'-d] thiophene groups (Figure 5). Their polymer films, produced via electropolymerization of co-monomers in trifluroborate-diethyl ether and acetonitrile, were characterized experimentally, and their band gaps were obtained to be 2.04 and $1.86 \mathrm{eV}$, respectively, by in situ spectro-electrochemical measurements. Molecular orbitals and electropolymerization of the co-monomers were elaborated by means of DFT level computations. While 6-31+G(d,p) basis set with MN12-SX method, one of Meta-GGA DFT functionals, was applied on neutral molecules, unrestricted MN12-SX with the same basis set was used for their radical cations. Solvent effect was also included in the calculations with integral equation formalism of the Polarizable Continuum Model (IEFPCM). The absorption maxima of the monomers NBT and $\mathrm{Ph}_{2} \mathrm{DTT}$ were recorded as $234,332 \mathrm{~nm}$ and 260, $293 \mathrm{~nm}$, respectively, which were explained according to TD-DFT level calculations at (IEFPCM:DCM)-TD-MN12-SX/6-31+G(d,p) level, providing 219, $335 \mathrm{~nm}$ and 260, $318 \mathrm{~nm}$ absorptions with main contributions from HOMO to LUMO excitations. The results obtained computationally are in well agreement with the experimentally recorded absorption values. Both optical investigations and DFT level predictions provided the band gaps of NBT- $\mathrm{Ph}_{2} \mathrm{DTT}-\mathrm{NBT}$ (16) and $\mathbf{1 5}$ as $2.76 \mathrm{eV}$ and $2.64 \mathrm{eV}$, respectively. For 14, while optical band gap of $2.58 \mathrm{eV}$ was obtained experimentally, theoretical studies provided the band gap of $2.44 \mathrm{eV}$. Computational studies indicated a smooth electro-polymerization starting generally from $\alpha$-carbons of the explored compounds.
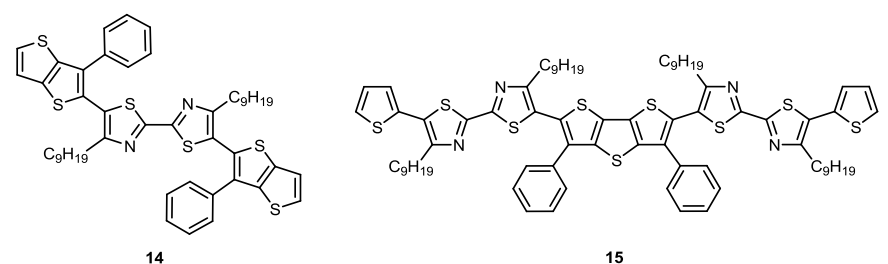

15

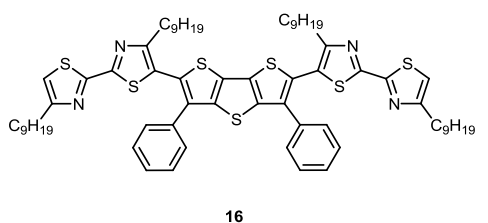

16

Figure 5. PhTT-NBT-PhTT (14) T-NBT-Ph ${ }_{2}$ DTT-NBT-T (15) and NBT-Ph ${ }_{2}$ DTT-NBT (16) comonomers investigated for electropolymerization. ${ }^{54,55}$

Buyruk et $\mathrm{al}^{56}$ investigated the properties of donor-acceptor (D-A) copolymers possessing TT/DTT as electron donating units and 1,2,3-triazole as an acceptor. Systematic studies on their optoelectronic and electrochemical properties provided the corresponding band gaps varying from 2.2 to $2.8 \mathrm{eV}$. (TD)-(CPCM:THF)-B3LYP/6-31G(d) level computations performed on the model compounds, which unveiled the presence of an intramolecular charge transfer transition between TT/DTT units and 1,2,3-triazole group (Figure 6).

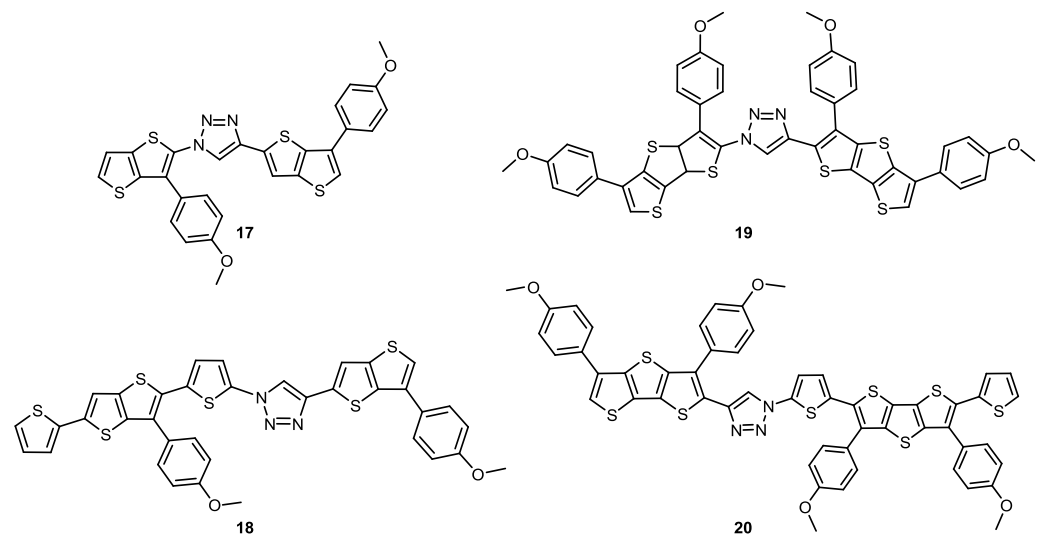

Figure 6. Model compounds 17-20 containing TT/DTT donors and 1,2,3-triazole acceptor for DFT computations. ${ }^{56}$

Instead of heteroaromatic unit such as 2,2'-bithiazole, successfully incorporated into TT and DTT molecules to make the electropolymerization feasible, ${ }^{54,55}$ Turkoglu et al ${ }^{57}$ utilized boron as a strong acceptor in their OLED molecules. They analyzed the photophysical and 
electrochemical properties of novel organoboron compounds 21-23, possessing conjugated TT as a $\pi$-conjugated spacer between mesitylboron acceptor and triphenylamine (TPA) donor units (Figure 7). The ground state geometric optimizations, optical band gaps, wavelength absorption maxima and fluorescence spectra of compounds $\mathbf{2 1 - 2 3}$ were investigated computationally by performing (TD)-DFT calculations at B3LYP/ 6-31G(d) level. While the $\lambda_{\max }$ values of 21-23 were calculated to be 425,474 and $528 \mathrm{~nm}$, with the incorporation of solvent effect (THF), their $\lambda_{\text {em }}$ values were estimated as 519,544 and $582 \mathrm{~nm}$, respectively. For all the organoboron compounds 21-23, experimental data (absorption maxima: 390, 411 and 454, emission maxima: 502,520 and 545, respectively) are well in agreement with the computational results.
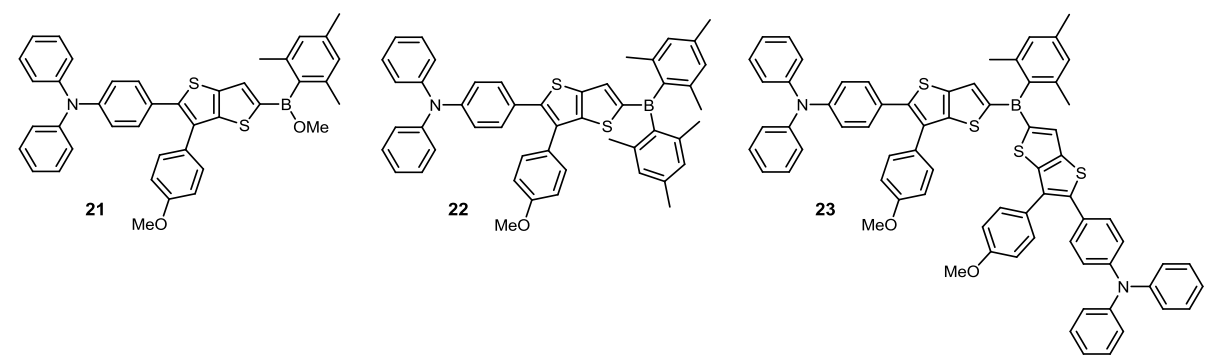

Figure 7. Organoboron compounds 21-23. ${ }^{57}$

Sahin et al ${ }^{58}$ used heteroatom boron as an acceptor in their seven soluble polymers 24-30 connecting substituted-TT donors (Figure 8). These compounds were reported as a first example of TT-boron copolymers emitting white color. The structural and electronic states of the polymers were elaborated by performing DFT and TD-DFT calculations on dimers and trimers at B3LYP/6-31G level. Their UV-Vis absorption spectra and vertical excitation energies were predicted using the TD-DFT method with solvent effect (THF). DFT level computations indicated an intramolecular charge transfer transitions between donor TT units and boron acceptor groups. Furthermore, the estimated absorption and emission spectra of the dimers and trimers matched well with the experimental results. For example; the UV-Vis absorption maxima of $\mathbf{2 4}$ measured in THF were 390 and $295 \mathrm{~nm}$, while excited state electronic transitions predicted at (PCM:THF)-TD-B3LYP/6-31G(d) level were calculated as 418 and $282 \mathrm{~nm}$.

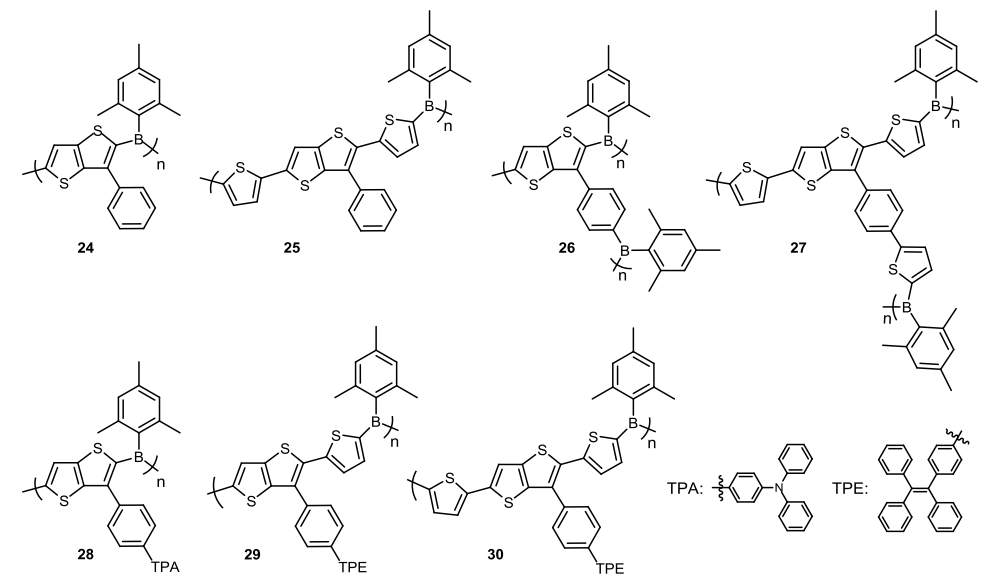

Figure 8. Polymers $\mathbf{2 4}-\mathbf{3 0}$ possessing TT and mesitylboron units. ${ }^{58}$ 


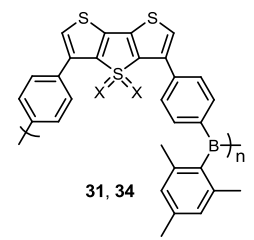

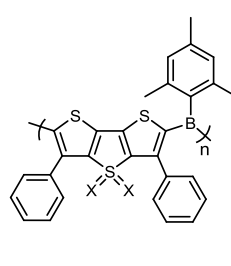

32,35

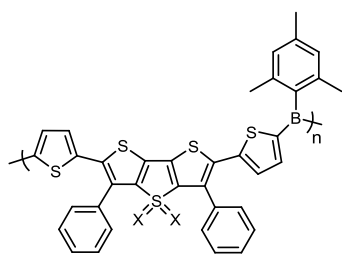

33,36

Figure 9. Polymers 31-36 having DTT and DTT- $S, S$-dioxide units connected via mesitylboron. ${ }^{59}$
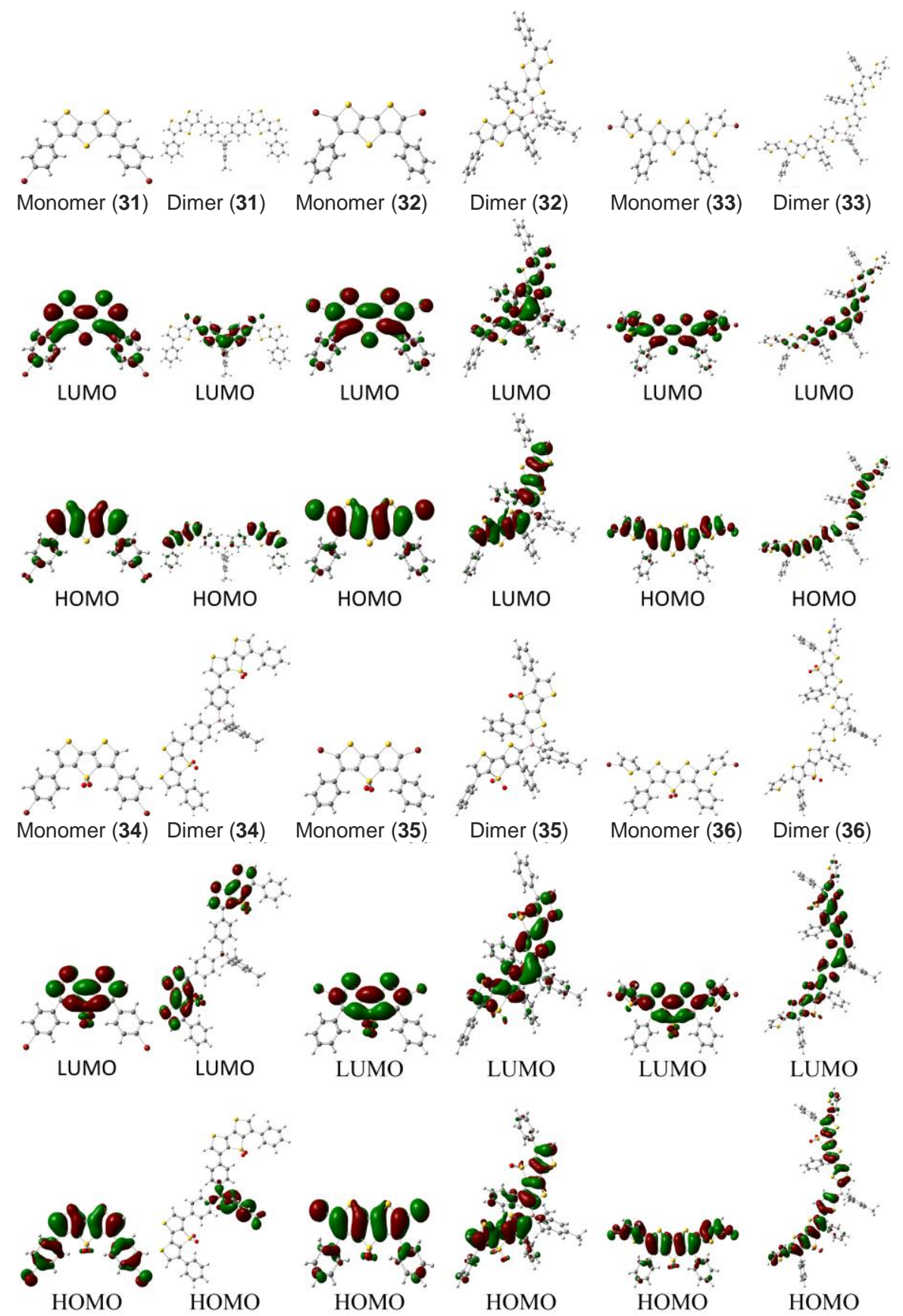

Figure 10. HOMO and LUMOs (isosurface value $=0.025 \mathrm{au}$ ) of monomers and dimers predicted at B3LYP/6-31G(d) level in gas phase. "Reprinted (adapted) with permission from Sevinis, E. B.;

Sahin, C.; Cinar, M. E.; Eroglu, M. S.; Ozturk, T. Polym. Eng. Sci., 2016, 56, 1390-1398. Copyright 2016 John Wiley and Sons." ${ }^{15}$ 
Sevinis et al ${ }^{59}$ applied this methodology on DTT and DTT-4,4-dioxide (DTT-S,S-O ${ }_{2}$ ) to achieve their copolymers with mesitylboron for potential applications in optoelectronic devices (Figure 9). Structural and electronic states of the model compounds, which were prepared as dimers, having boron acceptor units between DTT donor groups, were unveiled by conducting DFT method in order to shed more light on their optical properties (Figure 10). While HOMOs of all the molecules, except that of dimer 34, are localized on DTT donor units, LUMOs of the dimers are exclusively located on boron acceptor atoms with small contributions of DTT groups. The UV-Vis absorption spectra and vertical excitation energies of the dimers and their emission spectra were predicted at (PCM:THF)-TD-DFT level, which are well in alignment with the experimental absorption and emission values. While optical band gaps were obtained between 2.46 and $3.21 \mathrm{eV}$ for 31-36, the estimated values ranged from 2.34 to $3.25 \mathrm{eV}$.

\section{Thiophene-Based Fused Heteroacenes}

\subsection{Structural and Electronic Properties of Thiophene-Based Fused Heteroacenes and Their Applications}

One of the focus areas for the development of new materials has been continuing to be acenes and fused heteroacenes. Recent synthetic efforts have been devoted to the development of acene-based materials having better chemical stability and solution proccesability. ${ }^{60}$ When chemically unstable large polyacenes such as pentacene, hexacene, heptacene, etc. are transformed to thiophene-based fused heteroacenes via thiophene rings, new modified structures simultaneously exhibit good stability and high charge carrier mobility. ${ }^{61,62}$ Thiophene based heteroacenes, compared to carbon analogue polyacenes, are expected to be more stable in air, more soluble, provide high transistor performance and good packing in solid state. In addition, they are easily modified at thiophene units. ${ }^{63,64}$

Heteroaromatic oligomers widely used in organic-based electronic devices have received remarkable attention owing to their unique photophysical properties and their good stabilities against photo-degradation and oxidation processes. ${ }^{65-68}$ Although the synthesis of benzannulated fused oligothiophenes, derivatives of heteroacenes, is not straightforward, they have interesting properties including their strong intermolecular interactions. They also exhibit strong performances as p-channel organic semiconductors. ${ }^{69,70}$ New thienoacene-based organic semiconductors possessing benzothiophene showed very high mobility exceeding $10 \mathrm{~cm}^{2} \mathrm{~s}^{-1} \mathrm{~V}^{-1}$, which could be expected to expand horizons of organic semiconductors. ${ }^{71}$

Thiophene-based fused heteroacenes containing different heteroatoms such as - silole, ${ }^{72,73}$ borole ${ }^{74,75}$ and -phosphole ${ }^{76,77}$ have also received considerable attention as key components of organic materials for construction of optical and electronic devices.

Some of heteroacenes derivatized from acenes and thiophene rings such as tetraceno[2,3$b]$ benzo $[d]$ thiophene (TBT, 38 $)^{78}, 2,5$ di[thieno[3,2- $\left.b\right][1]$ benzothiophenic-2-]thiophene (DTBTT, 39) ${ }^{79}$, bis[1]benzothieno[2,3-d;2',3'-d']benzo[1,2-b;4,5- $\left.b^{\prime}\right]$ dithiophene (BBTBDT, 40 ${ }^{69}$ bis(naphtho[2,3-b]thieno)[2,3-d;2',3'- $\left.d^{\prime}\right]$ benzo[1,2- $\left.b ; 4,5-b^{\prime}\right]$ dithiophene (BNTBDT, 41 ${ }^{80}$ and dibenzo[ $\left[d, d^{\prime}\right]$ thieno[3,2-b;4,5- $\left.b^{\prime}\right]$ dithiophene (DBTDT, 42$)^{62}$, are shown in Figure 11. Thienoacene co-oligomers and thiophene-fused acenes are very appealing for maximizing the overlap of $\pi$-orbitals by reducing the free rotation around the single bonds in thiophene oligomers, which results in a densely packed crystal structure with face-to-face $\pi$-stacking motifs. Recently, naphthalene, anthracene, tetracene and fluorene, etc., have been successfully introduced into oligothiophene via co-oligomerization. They were used as excellent stable semiconductor materials with relatively high band gaps and low energy level HOMOs. 


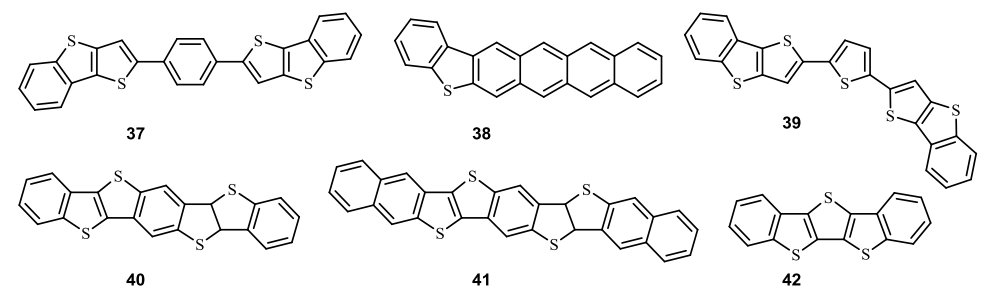

Figure 11. Some of thiophene-based fused heteroacenes $\mathbf{3 7 - 4 2}$. $^{62,69,72,78,80}$

\subsection{Computational Studies on Thiophene-Based Fused Heteroacenes}

In parallel with the recent experimental work on thiophene based fused heteroacenes, theoretical efforts have indeed started to become a major source of valuable information that complements experimental studies, thereby contributes to the understanding of the molecular electronic structures as well as the optoelectronic properties of the materials. ${ }^{81,82}$

Sokolov et $\mathrm{al}^{83}$ demonstrated that novel derivatives of the dinaphtho[2,3- $\left.b: 2^{\prime}, 3^{\prime}-f\right]$ thieno$[3,2-b]$ thiophene with high hole mobility and air stability can be used as a high performance semiconductor (Figure 12). Geometries of the neutral ground state and radical cations were optimized at B3LYP/6-31G(d,p) level. To shed light on the crystal structure, which is an important feature for OFET applications, properties of the isolated molecules in a unit cell were calculated by Perdew-Burke-Ernzerhof parametrization with the double numeric plus polarization basis $(\mathrm{PBE} / \mathrm{DNP})$ and $\mathrm{B} 3 \mathrm{LYP} / 6-311+\mathrm{G}(\mathrm{d}, \mathrm{p})$ methods. The screening procedures were performed for compounds $\mathbf{4 4 - 5 0}$, which are potential derivatives of compound $\mathbf{4 3}$, such as (i) computational screening for small reorganization energy possessing molecules, (ii) optimization of crystal structure, (iii) calculation on charge transport providing relative mobilities, (iv) picking up the potential molecules having the highest mobility, (v) realizing the synthesis and (vi) fabrication of the device and investigations of its properties. According to computational results, 2 was a potential candidate owing to its higher transfer integral. Therefore, its synthesis and characterization were performed for single-crystal OFET devices, which provided saturation region hole mobilities as high as $12.3 \mathrm{~cm}^{2} \mathrm{~V}^{-1} \mathrm{~s}^{-1}$ and a linear region mobility of $16.0 \mathrm{~cm}^{2} \mathrm{~V}^{-1} \mathrm{~s}^{-1}$.
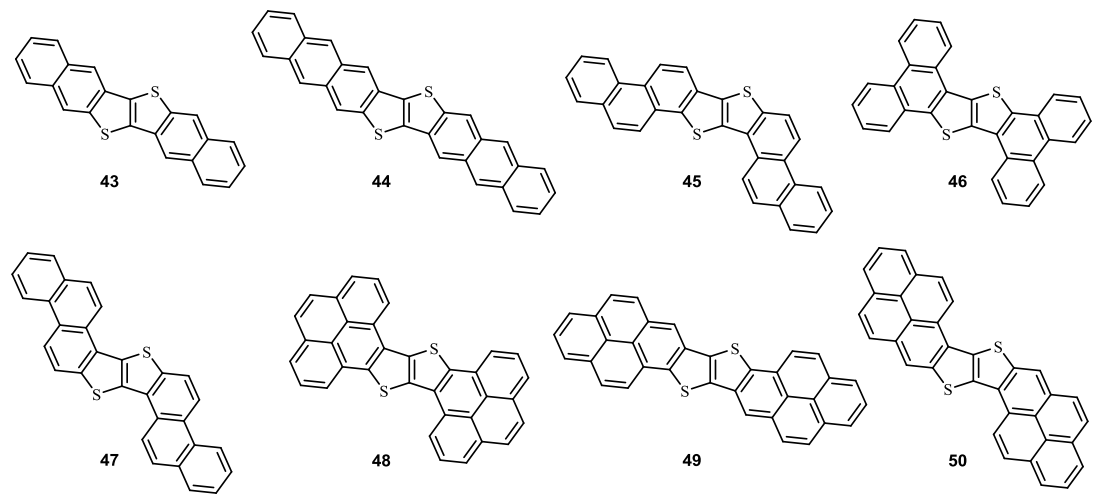

Figure 12. The structures of the studied heteroacenes $\mathbf{4 3 - 5 0} .^{83}$

Electron rich benzodithiophene, coupled with electron deficient TT isomer, namely thieno[3,4-b]thiophene via a single bond, was also considered in material chemistry. Borges et $\mathrm{al}^{84}$ reported structural and electronic properties of the ground and lowest excited states of poly(thieno[3,4-b]thiophenebenzodithiophene) (51) by help of high-level theoretical investigations (Figure 13). Although TDDFT is an efficient method for computing the electronic spectra of such large $\pi$-conjugated polymers, its excited charge transfer (CT) state description was considered to be poor. To amend this feature, the algebraic diagrammatic construction method to second order, $\mathrm{ADC}(2)$, was introduced, which is a combination of $a b$ initio wave-function-based polarization propagator method with resolution of identity (RI) method. $\mathrm{ADC}(2)$ was used to predict data for excited state energies, oscillator strengths and bond length alternation (BLA) analysis. The results 
obtained from $\mathrm{ADC}(2)$ were compared with TD-DFT outcomes at B3LYP, CAM-B3LYP, BHandHLYP, PBE and LC-wPBE levels. With regard to excitation energies, CAM-B3LYP and BHandHLYP provided the best matching with the results estimated using $\operatorname{ADC}(2)$.

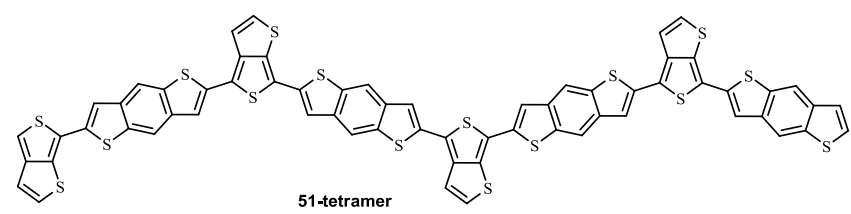

Figure 13. Chemical structure of 51-tetramer. ${ }^{84}$

Simone et $\mathrm{a}^{85}$ investigated a series of fused thiophene-pyrrole ring systems, so-called $\mathrm{S}, \mathrm{N}$ heteroacenes $(\mathbf{5 2 - 5 8}, \mathrm{SN} n, n=6-12,14$, Figure 14) by means of DFT methods at different exchange-correlation functionals. Frequencies and molecular geometries of SN6-SN10 (52-57) were calculated at the M06, B3LYP-D3, PBE03, wB97XD, CAM-B3LYP and OPBE exchangecorrelation functionals with all the valence $6-31 \mathrm{G}(\mathrm{d})$ basis set. Percentage errors are listed in Table 1. The electronic spectra of neutral, radical cation and dication species have been obtained using TDDFT. According to computational results; (i) absolute error of excitation energies in all exchange-correlation functionals, except $\mathrm{PBE03}$, increased with the molecular size, (ii) percentage errors obtained from wB97XD, OPBE and CAMB3LYP calculations were higher than the others, (iii) M06, PBE0 and B3LYP-D3 reproduced the experimental data very well with percentage errors varying from 0.26 to 2.90 . This excellent agreement was constant along all the considered molecules, (iv) the ionization potentials decreased along the series reaching the lower value for 57, (v) N-alkylated substituents in the synthesized molecules did not affect significantly the absorption properties.

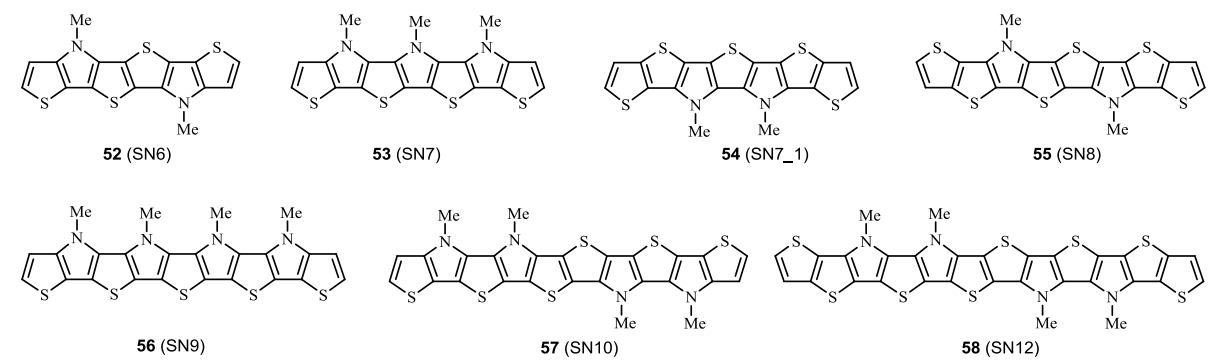

Figure 14. Chemical structure of $\mathrm{S}, \mathrm{N}$-heteroacenes $\mathbf{5 2}-\mathbf{5 8} .^{85}$

Table 1. Percentage errors obtained from TD-DFT methods with 6-31G(d) basis set compared to experimental absorption wavelengths ( $\mathrm{nm})$.

\begin{tabular}{lccccccc}
\hline & M06 & B3LYPD3 & PBE03 & OPBE & wB97XD & CAMB3LYP & Exp $^{86,87}$ \\
\hline $\mathbf{5 2}$ (SN6) & 0.26 & 0.26 & 2.90 & 6.33 & 9.76 & 8.18 & 379 \\
$\mathbf{5 3}$ (SN7) & 1.28 & 1.02 & 2.55 & 9.20 & 11.5 & 9.46 & 391 \\
$\mathbf{5 4}$ (SN7_1) & 1.01 & 2.02 & 1.77 & 10.1 & 10.6 & 8.86 & 395 \\
$\mathbf{5 5}$ (SN8) & 0.96 & 2.17 & 1.45 & 10.9 & 10.6 & 8.95 & 413 \\
$\mathbf{5 6}$ (SN9) & 2.14 & 2.38 & 1.66 & 12.6 & 12.4 & 10.0 & 420 \\
$\mathbf{5 7}$ (SN10) & 1.60 & 2.75 & 1.15 & 13.1 & 12.4 & 9.86 & 436 \\
\hline
\end{tabular}

\section{Conclusion}

Fused thiophenes comprising thienthiophene, ditihienothiophene, thienoacene, and other thiophene based fused heteroacenes have been the interest of scientists owing to their promising properties in material chemistry. The experimental studies including their design, synthesis, characterization and determinations of their properties have been performed extensively. 
Nevertheless, to shed more light on their characteristics and open a new avenue for their proper use, computational investigations have been conducted. Especially, DFT, which is known to be an efficient and relatively cheap method compared ab initio tools, has been selected in numerous research fields to unveil and provide back up for experimental outcomes. Among DFT methods B3LYP functional is generally employed due to the good agreement between predicted and the experimental results.

\section{Acknowledgements}

We thank The Scientific and Technological Research Council of Turkey (TUBITAK) for supporting this work (111T075 and 114Z202) and Istanbul Technical University, Turkey, for a grant to F. Dikcal (PhD). M. E. Cinar is grateful to TUBITAK for Postdoctoral Research Fellowships BIDEB 2216 program. Unsped Global Logistic is gratefully acknowledged for financial support.

\section{References}

[1] Katz, H. E.; Bao, Z.; Gilat, S. L. Synthetic Chemistry for Ultrapure, Processable, and HighMobility Organic Transistor Semiconductors.Acc. Chem. Res., 2001, 34, 359-369.

[2] Wang, C.; Dong, H.; Hu, W.; Liu, Y.; Zhu, D. Semiconducting $\pi$-Conjugated Systems in FieldEffect Transistors: A Material Odyssey of Organic Electronics. Chem. Rev., 2012, 112, 2208-2267.

[3] Dong, H.; Wang, C.; Hu, W. High performance organic semiconductors for field-effect transistors.Chem. Commun., 2010, 46, 5211-5222.

[4] Kang, B.; Lee, W. H.; Cho, K. Recent Advances in Organic Transistor Printing Processes. Appl. Mater. Interfaces, 2013, 5, 2302-2315.

[5] Brabec, C. J.; Heeney, M.; McCulloch, I.; Nelson, J. Influence of blend microstructure on bulk heterojunction organic photovoltaic performance. Chem. Soc. Rev., 2011, 40, 1185-1199.

[6] Cheng, Y.-J.; Yang, S.-H.; Hsu, C.-S. Synthesis of Conjugated Polymers for Organic Solar Cell Applications. Chem. Rev., 2009, 109, 5868-5923.

[7] Mishra, A.; Bäuerle, P. Small Molecule Organic Semiconductors on the Move: Promises for Future Solar Energy Technology. Angew. Chem. Int. Ed., 2012, 51, 2020-2067.

[8] Arias, A. C.; MacKenzie, J. D.; McCulloch, I.; Rivnay, J.; Salleo, A. Materials and Applications for Large Area Electronics: Solution-Based Approaches. Chem. Rev., 2010, 110, 3-24.

[9] Cinar, M. E.; Ozturk, T. Thienothiophenes, Dithienothiophenes, and Thienoacenes: Syntheses, Oligomers, Polymers, and Properties. Chem. Rev., 2015, 115, 3036-3140.

[10] Cinar, M. E.; Ozturk, T. Fused Thiophenes and Some Oligomers and Polymers Therefrom, Ed. John A. Joule, Thiophenes, Springer-Verlag Berlin Heidelberg, 2014, 161-202.

[11] Litvinov, V.P. The latest achievements in thienothiophene chemistry. Russ. Chem. Rev., 2005, 74, $217-248$.

[12] Li, L; Zhao, C.; Wang, H. Recent Progress in Synthesis and Application of Thiophene Oligomers Based on BithiopheneDicarbanions. Chem. Rec .2016, 16, 797-809.

[13] Lim, S. T.; Kwon, M. S.; Shin, D. M. Organic Light Emitting Diodes (OLEDs) with Oligothiophene and Silicon Monoxide. Mol. Cryst. and Liq. Cryst., 2001, 371, 171-176.

[14] Kulkarni,. A. P.; Tonzola, C. J.; Jenekhe, S. A. Electron Transport Materials for Organic LightEmitting Diodes. Chem. Mater. 2004, 16, 4556-4573.

[15] Cho, J. S.; Kojima, Y.; Yamamoto, K. A novel oligothiophene derivative as a hole-transport with emitting material for OLED. Polym.Adv.Technol., 2003, 14, 52-57.

[16] Fujisaki, Y.; Nakajima, Y.; Takei, T.; Fukagawa, H.; Yamamoto, T.; Fujikake, H. Flexible ActiveMatrix Organic Light-Emitting Diode Display Using Air-Stable Organic Semiconductor of Dinaphtho[2, 3-b:2',3'-f]thieno[3, 2-b]-thiophene. IEEE Trans. Electron Devices, 2012, 59, 3342-3349.

[17] Pei, J.; Yu, W. L.; Ni, J.; Lai, Y. H.; Huang, W.; Heeger, A. J. Thiophene-Based Conjugated Polymers for Light-Emitting Diodes: Effect of Aryl Groups on Photoluminescence Efficiency and Redox Behavior. Macromolecules, 2001, 34, 7241-7248. 
[18] Sakai, J.; Taima, T.; Saito, K. Efficient oligothiophene:fullerene bulk heterojunction organic photovoltaic cells. Org. Electron., 2008, 582-590.

[19] Kong, J. A.; Lim, E.; Lee, K. K.; Lee, S.; Kim, S. H. A benzothiadiazole-based oligothiophene for vacuum-deposited organic photovoltaic cells. Sol. Energy Mater. Sol. Cells, 2010, 94, 2057-2063.

[20] Bedis, H.; Kouki, F.; Bouchriha, H. Effect of the oligothiophene chain length on the performance of organic photovoltaic cells. Appl Phys A., 2013, 110, 163-171.

[21] Shin, N.; Yun, J.; Yoon, Y.; Son, J. H.;.Ju, S. Y.; Kwon, S. K.; Kim, B.; Kim, Y. H. Highly Stable Polymer Solar Cells Based on Poly(dithienobenzodithiophene-co-thienothiophene). Macromolecules, 2015, 48, 3890-3899.

[22] Kumaresan, P.; Vegiraju, S.; Ezhumalai, Y.; Yau, S. L.; Kim, C.; Lee, W. S.; Chen, M. C. FusedThiophene Based Materials for Organic Photovoltaics and Dye-Sensitized Solar Cells Polymers, 2014, 6, 2645-2669.

[23] Fang, H. P.; Chiang, I. H.; Chu, C. W.; Yang, C. C.; Lin, H. C. Applications of novel dithienothiophene- and 2,7-carbazole-based conjugated polymers with surface-modified $\mathrm{ZnO}$ nanoparticles for organic photovoltaic cells. Thin Solid Films, 2011, 5212-5218.

[24] Zen, A.; Pingel, P.; Jaiser, F.; Neher, D.; Grenzer, J.; Zhuang, W.; Rabe, J. P.; Bilge, A.; Galbrecht, F.; Nehls, B. S.; Farrell, T.; Scherf, U.; Abellon, R. D.; Grozema, F. C.; Siebbeles, L. D. A. Organic Field-Effect Transistors Utilizing Solution-Deposited Oligothiophene-Based Swivel Cruciforms. Chem. Mater., 2007, 19, 1267-1276.

[25] Sirringhaus,H.; 25th Anniversary Article: Organic Field-Effect Transistors: The Path Beyond Amorphous Silicon Adv. Mater. 2014, 26, 1319-1335

[26] Takamiya, K.; Ishikawa, S.; Adachi, D.; Oku, S.; Nagamatsu, S.; Takashima, W.; Hayase, H.; Kaneto, K. Bis(alkyl-thiophene) thienothiophene as hole-transport organic semiconductor. Physics Procedia, 2011, 14, 182-186.

[27] Zhang, L.; Tan, L.; Wang, Z.; Hu, W.; Zhu, D. High-Performance, Stable Organic Field-Effect Transistors Based on trans-1,2-(Dithieno[2,3-b:3',2'-d]thiophene)ethene. Chem. Mater., 2009, 21, 1993-1999.

[28] Kwon, T. H.; Armel, V.; Nattestad, A.; MacFarlane, D. R.; Bach, U.; Lind, S. L.; Gordon, K. C.; Tang, W.; Jones, D. J.; Holmes, A. B.Dithienothiophene (DTT)-Based Dyes for Dye-Sensitized Solar Cells: Synthesis of 2,6-Dibromo-DTT. J. Org. Chem., 2011, 76, 4088-4093.

[29] Nakayama, K.; Hirose, Y.; Soeda, J.; Yoshizumi, M.; Uemura, T.; Uno, M.; Li, W.; Kang, M. J.; Yamagishi, M.; Okada, Y.; Miyazaki, E.; Nakazawa Y.; Nakao, A.; Takimiya, K.; Takeya, J. Patternable Solution-Crystallized Organic Transistors with High Charge Carrier Mobility. Adv Mater., 2011, 23, 1626-1629.

[30] Minemawari, H., Yamada, T., Matsui, H., Tsutsumi, J., Haas, S., Chiba, R., Kumai, R. and Hasegawa, T. Inkjet Printing of Single-Crystal Films. Nature, 2011, 475, 364-367.

[31] Skabara, P.J. In Handbook of Thiophene-based Materials; Perepichka, I. F.; Perepichka, D. F. Eds.; John Wiley \& Sons: Chichester, U.K., 2009; Chapter 3.

[32] Li, W.; Guo, Y.; Shi, J.; Yu, H.; Meng, H. Solution-Processable Neutral Green Electrochromic Polymer Containing Thieno[3,2-b]thiophene Derivative as Unconventional Donor Units. Macromolecules, 2016, 49, 7211-7219.

[33] Youn, J.; Vegiraju, S.; Emery, J. D.; Leever, B. J.; Kewalramani, S.; Lou, S. J.; Zhang, S.; Prabakaran, K.; Yamuna, E.; Kim, C.; Huang, P, Y.; Stern, C.; Chang, W. C.; Bedzyk, M. J.; Chen, L. X.; Chen, M. C.; Facchetti, A.; Marks, T. J. Diperfl uorophenyl Fused Thiophene Semiconductors for n-Type Organic Thin Film Transistors (OTFTs). Adv. Electron. Mater. 2015, $1,1500098$.

[34] Yi, W.; Zhao, S.; Sun, H.; Kanb, Y.; Shi, J.; Wang, S.; Li, C.; Wang, H. Isomers of organic semiconductors based on dithienothiophenes:the effect of sulphur atoms positions on the intermolecular interactions and field-effect performances. J. Mater. Chem. C, 2015, 3, 10856-10861.

[35] Li, X. C.; Sirringhaus, H.; Garnier, F.; Holmes, A. B.; Moratti, S. C.; Feeder, N.; Clegg, W.; Teat, S. J.; Friend, R. H. A Highly $\partial$-Stacked Organic Semiconductor for Thin Film Transistors Based on Fused Thiophenes. J. Am. Chem. Soc. 1998, 120, 2206-2207.

[36] Li, J.; Tan, H. S.; Chen, Z. K.; Goh, W.P.; Wong, H. K.; Ong, K. H.; Liu, W.; Li, C. M.; Ong, B. S. Dialkyl-Substituted Dithienothiophene Copolymers as Polymer Semiconductors for Thin-Film Transistors and Bulk Heterojunction Solar Cells. Macromolecules, 2011, 44, 690-693. 
[37] Krayushkin, M. M.; Stoyanovich, F. M.; Zolotarskaya, O. Y.; Yarovenko, V. N.; Bulgakova, V. N.; Zavarzin, I. V.; Martynkin A. Y. New approach to the synthesisof dithienothiophene and preparation of its photochromic derivative. Russ. Chem. Bull., 2002, 51, 2097-2099.

[38] Ozturk, T.; Ertas, E.; Mert, O. Dithienothiophenes. Tetrahedron, 2005, 61, 11055-11077.

[39] Anthony, J. E. The Larger Acenes: Versatile Organic Semiconductors. Angew. Chem. Int. Ed., 2008, 47, 452-483.

[40] Sun, Z.; Ye, Q.; Chi, C.; Wu, J. Low band gap polycyclic hydrocarbons: from closed-shell near infrared dyes and semiconductors to open-shell radicals. Chem. Soc. Rev., 2012, 41, 7857-7889.

[41] Portella, G.; Poater, J.; Bofill, J. M.; Alemany, P.; Solà, M. Local Aromaticity of [n]Acenes, [n]Phenacenes, and [n]Helicenes (n = 1-9). J. Org. Chem., 2005, 70, 2509-2521.

[42] Di, C.; Yu, G.; Yunqi, Y.; Zhu, D. High-Performance Organic Field-Effect Transistors: Molecular Design, Device Fabrication, and Physical Properties. J. Phys. Chem. B, 2007, 111, 14083-14096.

[43] Bao ,Q.; Lu, Z.; Li, J.; Loh, K. P.; Li, C. M. Theoretical and Experimental Studies of Electronic Transport of Dithienothiophene. J. Phys. Chem. C., 2009, 113, 12530-12537.

[44] Ozen, C.; Yurtsever, M.; Ozturk, T. A theoretical approach to the formation mechanism of diphenyldithieno[3,2-b:2',3'-d] thiophene from 1,8-diketone, 4,5-bis(benzoylmethylthio)thiophene: a DFT study. Tetrahedron, 2011,67, 6275-6280

[45] Casado, J.; Hernández, V.; Kim, O.-K.; Lehn, J.-M.; Lopey Navarrete, J. T.; Ledesma, S. D.; Ortiz, R. P.; Ruiz Delgado, M. C.; Vida, Y.; Pérez-Inestrosa, E. Vibrational and QuantumChemical Study of Nonlinear Optical Chromophores Containing Dithienothiophene as the Electron Relay. Chem. Eur. J., 2004, 10, 3805-3816.

[46] Ortiz, R. P.; Ruiz Delgado, M. C.; Casado, J.; Hernández, V.; Kim O.-K.; Woo, H. Y.; López Navarrete, J. T. Electronic Modulation of Dithienothiophene (DTT) as $\pi$-Centerof D- $\pi$-D Chromophores on Optical and Redox Properties: Analysis by UV-Vis-NIR and Raman SpectroscopiesCombined with Electrochemistry and Quantum Chemical DFT Calculations. J. Am. Chem. Soc., 2004, 126, 13363-13376.

[47] Li, P.; Cui, Y.; Song, C.; Zhang, H. Electronic and Charge Transport Properties of Dimers of Dithienothiophenes: Effect of Structural Symmetry and Linking Mode. RSC Adv., 2015, 5, 50212-50222.

[48] Taskiran Cankaya, S.; Capan, A.; Cinar, M. E.; Akin, E.; Topal, S.; Ozturk, T. Syntheses and Properties of 3,4-Diaryl-dithieno[2,3-b;3',2'-d] thiophenes. J. Sulfur Chem., 2013, 34, 638-645.

[49] Ra, C. S.; Yim, S.; Park, G. DFT Studies of Band Gaps of the Fused Thiophene Oligomers. Bull. Korean Chem. Soc., 2008, 29, 891-893.

[50] Osuna, R. M.; Zhang, X.; Matzger, A. J.; Hernández, V.; Navarrete, J. T. L. Combined Quantum Chemical Density Functional Theory and Spectroscopic Raman and UV-vis-NIR Study of Oligothienoacenes with Five and Seven Rings. J. Phys. Chem. A., 2006, 110, 5058-5065

[51] Yang, L.; Ren, A. M.; Feng, J. K.; Wang, J. F. Theoretical Investigation of Optical and Electronic Property Modulations of $\pi$-Conjugated Polymers Based on the Electron-Rich 3,6-Dimethoxyfluorene Unit. J. Org. Chem., 2005, 70, 3009-3020.

[52] Fan, J.; Gathitu, N. N.; Chang, Y.; Zhang, J. Effect of length on the position of negative differential resistance andrealization of multifunction in fused oligothiophenes based molecular device. J. Chem. Phys, 2013, 138, 074307.

[53] Do, V. N.; Non-equilibrium Green function method: theory and application in simulation of nanometer electronic devices. Adv. Nat. Sci.: Nanosci. Nanotechnol., 2014, 5, 033001.

[54] Sezer, E.; Osken, I.; Cinar, M. E.; Demirel, O.; Ustamehmetoğlu, B.; Ozturk, T. Synthesis and Electropolymerization of Bis(phenylthieno[3,2-b]thiophenes)-(4,4'-dinonyl-2,2'-bithiazole) comonomer. Electrochim. Acta, 2016, 222, 1592-1603.

[55] Ustamehmetoğlu, B.; Osken, I.; Cinar, M. E.; Sezer, E.; Karaca, E.; Ozturk, T. Synthesis and Characterization of Dithienothiophene, Bithiazole and Thiophene Containing Polymer. Electrochim. Acta, 2017, 227, 435-446.

[56] Buyruk, A.; Cinar, M. E.; Eroglu, M. S.; Ozturk, T. ChemistrySelect, 2016, 1, 3028-3032.

[57] Turkoglu, G.; Cinar, M. E.; Buyruk, A.; Tekin, E.; Mucur, S. P.; Kaya, K.; Ozturk, T. Novel Organoboron Compounds Derived from Thieno[3,2-b]-thiophene and Triphenylamine Units for OLED Devices. J. Mater. Chem. C, 2016, 6045-6053.

[58] Sahin, O.; Cinar, M. E.; Tekin, E.; Mucur, S. P.; Topal, S.; Suna, G.; Eroglu, M. S.; Ozturk, T. White Light Emitting Polymers Possessing Thienothiophene and Boron Units. ChemistrySelect, 2017, in press. 
[59] Sevinis, E. B.; Sahin, C.; Cinar, M. E.; Eroglu, M. S.; Ozturk, T. Copolymers Possessing Dithienothiophene (DTT) and Boron for Optoelectronic Applications. Polym. Eng. Sci., 2016, 56, 1390-1398.

[60] Iino, H.; Usui, T.; Hanna, J. I. Liquid crystals for organic thin-film transistors. Nature Commun., 2015, 6, 6828-6835.

[61] Mori, T.; Nishimura, T.; Yamamoto, T.; Doi, I.; Miyazaki, E.; Osaka, I.; Takimiya, K. Consecutive Thiophene-Annulation Approach to $\pi$-Extended Thienoacene-Based Organic Semiconductors with [1]Benzothieno[3,2-b][1]benzothiophene (BTBT) Substructure. J. Am. Chem. Soc., 2013, 135, 13900-13913.

[62] Gao, J.; Li, R.; Li, L.; Meng, Q.; Jiang, H.; Li, H.; Hu, W. High-Performance Field-Effect Transistor Based on Dibenzo[ $\left.d, d^{\prime}\right]$ thieno[3,2-b;4,5- $\left.b^{\prime}\right]$ dithiophene, an Easily Synthesized Semiconductor with High Ionization Potential. Adv. Mater., 2007, 19, 3008-3011.

[63] Wex, B.; Kaafarani, B. R.; Kirschbaum, K.; Neckers, D. C. Synthesis of the anti and syn Isomers of Thieno[f,f]bis[1]benzothiophene. Comparison of the Optical and Electrochemical Properties of the anti and syn Isomers. J. Org. Chem., 2005, 70, 4502-4505.

[64] Xiong, Y.; Qiao, X.; Wu, H.; Huang, Q.; Wu, Q.; Li, J.; Gao, X.; Li, H. Syntheses and Properties of Nine-Ring-Fused Linear Thienoacenes. J. Org. Chem., 2014, 79, 1138-1144.

[65] Murphy, A. R.; Fréchet, J. M. J. Organic semiconducting oligomers for use in thin film transistors. Chem. Rev., 2007, 107, 1066-1096.

[66] Mishra, A.; Qi Ma, C.; Bauerle, P. Functional Oligothiophenes: Molecular Design for Multidimensional Nanoarchitectures and Their Applications. Chem. Rev., 2009, 109, 1141-1276.

[67] Ostroverkhova, O. Organic Optoelectronic Materials: Mechanisms and Applications. Chem. Rev., 2016, 116, 13279-13412.

[68] Takimiya, K. Shinamura, S.; Osaka, I.; Miyazaki, E. Thienoacene-Based Organic Semiconductors. Adv. Mater., 2011, 23, 4347-4370.

[69] Huang, J.; Luo, H.; Wang, L.; Guo, Y.; Zhang, W.; Chen, H.; Zhu, M.; Liu, Y.; Yu, G. Dibenzoannelated Tetrathienoacene: Synthesis, Characterization, and Applications in Organic Field-Effect Transistors.Org. Lett., 2012, 14, 3300-3303.

[70] Mitsudo, K.; Sato, H.; Yamasaki, A.; Kamimoto, N.; Goto, J.; Mandai, H.; Suga, S. Synthesis and Properties of Ethene-Bridged Terthiophenes. Org. Lett., 2015, 17, 4858-4861.

[71] Kurihara, N.; Yao, A.; Sunagawa, M.; Ikeda, Y.; Terai, K.; Kondo, H.; Saito, M.; Ikeda, H.; Nakamura, H. High-Mobility Organic Thin-Film Transistors Over $10 \mathrm{~cm}^{2} \mathrm{~s}^{-1} \mathrm{~V}^{-1}$ Fabricated Using Bis(benzothieno)naphthalene Polycrystalline Films. Jpn. J. Appl. Phys., 2013, 52, 05 DC11.

[72] Ohshita, J.; Lee, K. H.; Kimura, K.; Kunai, A. Synthesis of Siloles Condensed with Benzothiophene and Indole Rings. Organometallics, 2004, 23, 5622-5625.

[73] Ohshita, J. Group 14 metalloles condensed with heteroaromatic systems. Org. Photonics Photovolt., 2016, 4, 52-59.

[74] Iida, A.; Yamaguchi, S. Thiophene-Fused Ladder Boroles with High Antiaromaticity. J. Am. Chem. Soc., 2011, 133, 6952-6955.

[75] Kim, S.; Song, K.; Kang, S. O.; Ko, J. The role of borole in a fully conjugated electron-rich system Chem. Commun., 2004, 68-69.

[76] Dienes, Y.; Durben, S.; Karpati, T.; Neumann, T.; Englert, U.; Nyulaszi, L.; Baumgartner, T. Selective Tuning of the Band Gap of p-Conjugated Dithieno[3,2-b:2', $\left.3^{\prime}-d\right]$ phospholes toward Different Emission Colors. Chem.Eur. J., 2007, 13, 7487-7500.

[77] Fukazawa, A.; Murai, T. A.; Li, L.; Chen, Y.; Yamaguchi, S. Thiophene-fused phospholo[3,2-b]phospholes and their dichalcogenides: Synthesis and structure-photophysical properties relationships. C. R. Chimie, 2010, 13, 1082-1090.

[78] Du, C.; Guo, Y.; Chen, J.; Liu, H.; Liu, Y.; Ye, S.; Lu, K.; Zheng, J.; Wu, T.; Liu, Y.; Shuai, Z.; Yu, G. Design, Synthesis, and Properties of Asymmetrical Heteroacene and Its Application in Organic Electronics. J. Phys. Chem. C, 2010, 114, 10565-10571.

[79] Chen, H.; Cui, Q.; Yu, G.; Guo, Y.; Huang, J.; Zhu, M.; Guo, X.; Liu, Y. Synthesis and Characterization of Novel Semiconductors Based on Thieno[3,2-b][1]benzothiophene Cores and Their Applications in the Organic Thin-Film Transistors. J. Phys. Chem. C, 2011, 115, 2398423991.

[80] Yamamoto, T.; Nishimura, T.; Mori, T.; Miyazaki, E.; Osaka, I.; Takimiya, K. Largely $\pi$-Extended Thienoacenes with Internal Thieno[3,2-b]thiophene Substructures: Synthesis, Characterization, and Organic Field-Effect Transistor Applications. Org. Lett., 2012, 14, 4914-4917.

[81] Takimiya, K.; Osaka, I.; Nakano, M. pi-Building blocks for organic electronics: Revaluation of 
"inductive" and "resonance" effects of pi-electron deficient units. Chem. Mater., 2014, 26, 587593.

[82] Belghitia, N.; Bennania, M. N.; Bouzzineb, S. M.; Hamidib, M.; Bouachrinec, M. The DFT Chemical Investigations of Optoelectronic and Photovoltaic Properties of Short-Chain Conjugated Molecules. Phys. Chem. Res., 2014, 2, 11-20.

[83] Sokolov, A. N.; Atahan-Evrenk, S.; Mondal, R.; Akkerman, H. B.; Sánchez-Carrera, R. S.;Granados-Focil, S.; Schrier, J.; Mannsfeld, S. C. B.; Zoombelt, A. P.; Bao, Z.; Aspuru-Guzik, A. From computational discovery to experimental characterization of a high hole mobility organic crystal. Nat Commun., 2011, 2, 437-445.

[84] Borges, I., Jr.; Uhl, E.; Modesto-Costa, L.; Aquino, A. J. A.; Lischka, H. Insight into the Excited State Electronic and Structural Properties of the Organic Photovoltaic Donor Polymer Poly(thieno [3,4-b]thiophene benzodithiophene) by Means of ab Initio and Density Functional Theory. Phys. Chem. C, 2016, 120, 21818-21826.

[85] Simone, B. C. D.; Marino, T.; Prejanò, M.; Russo, N. Can fused thiophene-pyrrole-containing rings act as possible new electrochromic dyes? A computational prediction. Theor. Chem. Acc., 2016, 135, 238-247.

[86] Wetzel, C.; Brier, E.; Vogt, A.; Mishra, A.; Mena-Osteritz, E.; Bauerle, P. Fused ThiophenePyrrole containing ring systems up to a heterodecacene. Angew. Chem. Int. Ed., 2015, 54, 12334 12338.

[87] Mitsudo, K.; Shimohara, S.; Mizoguchi, J.; Mandai, H.; Suga, S. Synthesis of nitrogen-bridged terthiophenes by tandem Buchwald-Hartwig coupling and their properties. Org Lett., 2012, 14, $2702-2705$.

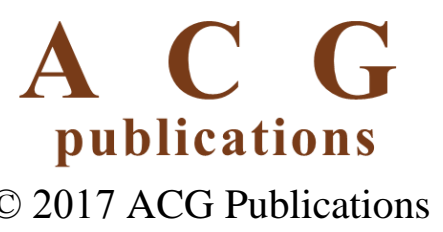

